\title{
Mini Sharing Literasi Keuangan dan Perpajakan Bagi Paguyupan Pengusaha Kecil Di Perumnas Kota Baru Driyorejo Gresik
}

\author{
Maria Assumpta Evi Marlina ${ }^{1}$, Anastasia Filiana Ismawati ${ }^{2}$, dan Kazia Laturette ${ }^{3}$ \\ 1,2,3 Universitas Ciputra Surabaya \\ * Penulis Korespondensi: E-mail: emarliana@ciputra.ac.id
}

\begin{abstract}
Accounting and Taxation Service Center Accounting Study ProgramCiputra University held a minisharing activity on financial literacy and taxation for small entrepreneurs in Perumnas Kota Baru Driyorejo (KBD) Gresik. The purpose of these activities is to add insight to small entrepreneurs in the field of financial literacy and taxation. Perumnas KBD Gresik was chosen based on the results of direct observation to the location. The field observation activity was assisted by the coordinator of the smallscale business enterprise of the KBD, Tezar Hariyanto. In that location there are small entrepreneurs who need additional insights related to financial and taxation literacy. Some entrepreneurs don't even understand how to manage their business finances. Some other entrepreneurs still do not understand about tax regulations in Indonesia, especially in individual tax reports. Through these activities, the small entrepreneurs get the opportunity to add insight into financial literacy and taxation. After participating in the activity, they realized that separating finance for household and business purposes was very important for the progress of his business. They also understand the importance of complying with the tax rules that apply in Indonesia.
\end{abstract}

Keywords: Mini Sharing, Financial Literacy, Taxation

\begin{abstract}
Abstrak
Kegiatan mini sharing yang diselenggarakan oleh Pusat Layanan Akuntansi dan Perpajakan Program Studi Akuntansi Universitas Ciputra bertujuan untuk memperluas wawasan para pemilik bisnis kecil di Perumnas Kota Baru Driyorejo (KBD) Gresik dalam bidang literasi keuangan dan perpajakan. Perumnas KBD Gresik dipilih berdasarkan hasil obeservasi langsung ke lokasi yang dibantu oleh koordinator pengusaha kecil Perumnas KBD yaitu Tezar Hariyanto. Dilokasi tersebut masih terdapat pengusaha kecil yang membutuhkan tambahan wawasan yang berhubungan dengan literasi keuangan dan perpajakan. Beberapa pengusaha bahkan belum paham cara mengelola keuangan usahanya. Beberapa pengusaha yang lain masih belum paham tentang peraturan perpajakan di Indonesia, khususnya dalam palaporan pajak perorangan. Melalui kegiatan tersebut, para pengusaha kecil mempunyai tambahan wawasan tentang literasi keuangan dan perpajakan. Setelah mengikuti kegiatan tersebut, mereka menyadari bahwa memisahkan keuangan untuk kepentingan rumah tangga dan bisnis merupakan hal yang sangat penting untuk kemajuan bisnisnya. Mereka juga menjadi paham pentingnya patuh terhadap aturan perpajakan yang berlaku di Indonesia.
\end{abstract}

Kata kunci: Mini Sharing, literasi Keuangan, Perpajakan

\section{PENDAHULUAN}

Layanan Akuntansi dan Perpajakan Program Studi Akuntansi Universitas Ciputra (PLAP-ACC-UC) mengadakan kegiatan mini sharing literasi keuangan dan perpajakan bagi anggota paguyuban pengusaha kecil di Perumnas Kota Baru Driyorejo Gresik Jawa Timur. Kegiatan tersebut dilakukan atas permintaan anggota paguyuban. Mereka menyampaikan 
bahwa mereka membutuhkan tambahan wawasan dalam merintis bisnis, mengembangkan binsis, mengelola keuangan, dan pengetahuan perpajakan.

Hal tersebut disampaikan secara jelas oleh lima orang anggota paguyuban, yang ditemui pelaksana kegiatan pada saat melakukan observasi. Empat orang menyampaikan bahwa mereka sudah berhasil merintis bisnis, tetapi mereka masih menemui kesulitan dalam pengembangan binisnya. Mereka juga masih belum paham pentingnya pemisahan keuangan antara keuangan bisnis dan keuangan keluarga. Mereka juga menyampaikan masih kesulitan dalam menentukan keuntungan atau kegurian bisnisnya. Seorang pengusaha yang telah bermitra dengan pemerintah menyatakan bahwa mereka belum paham cara membuat laporan keuangan dan membuat pelaporan pajak. Seorang anggota yang belum berhasil merintis bisnis menyampaikan keinginannya untuk mendapatkan tambahan wawasan untuk merintis bisnis. Berikut adalah salah satu gambar kegiatan observasi di lokasi.

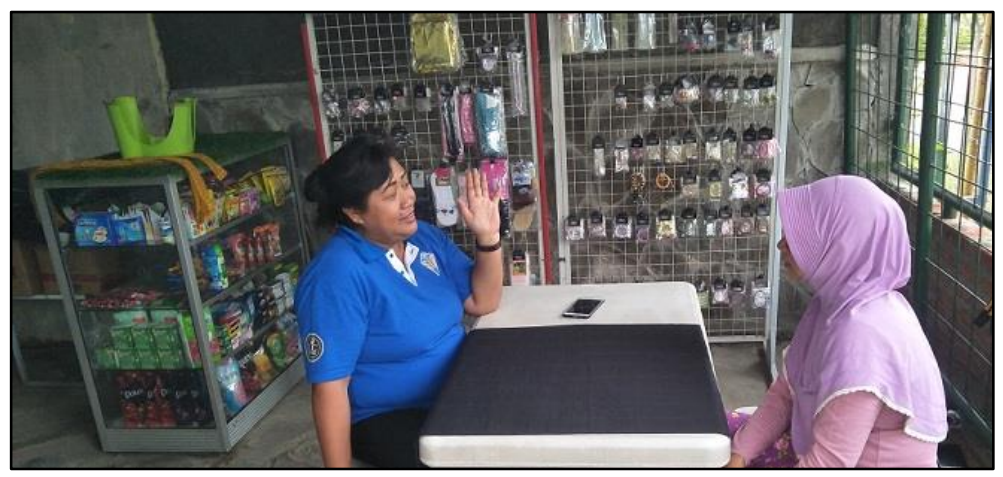

Gambar 1. Observasi Anggota Paguyuban Pedagang Kecil Perumnas Kota Baru Driyorejo Gresik

Hal-hal yang disampaikan para anggota paguyuban tersebut,menunjukkan bahwa tidak hanya kegiatan bisnis kecil di daerah terpencil yang perlu mendapatkan tambahan wawasan dan pendampingan, tetapi bisnis kecil di daerah pinggiran kota besarpun masih membutuhkan tambahan wawasan dan pendampingan. Warga dipinggiran kota besar seperti Surabaya, sebagian besar merupakan karyawan dan pengusaha. Perubahan profesi tersebut disebabkan karena adanya alih fungsi lahan pertanian menjadi lahan pemukiman dan lahan untuk industri (Pewista \& Harini, 2013; Pribadi \& Pauleit, 2015; Prihatin, 2015).

Oleh karena itu, kegiatan mini sharing literasi keuangan dan perpajakan perlu dilaksanakan bagi anggota paguyuban pengusaha kecil di Perumnas Kota Baru Driyorejo Gresik Jawa Timur. Kegiatan tersebut bertujuan untuk memperluas wawasan dan membekali tambahan pengetahuan bagi para pengusaha kecil tersebut. Kegiatan mini sharing tersebut berfokus pada 1) strategi pengembangan bisnis kecil; 2) pengenalan dan cara menyusun laporan keuangan usaha kecil; dan 3) pengenalan peraturan perpajakan di Indonesia dan cara pelaporannya. Melalui kegiatan tersebut diharapkan dapat membantu pengusaha kecil dalam mengembangkan bisnisnya; meningkatkan literasi keuangan dan perpajakan para pemilik bisnis; hingga dapat meningkatkan kesadaran mereka untuk patuh terhadap peraturan perpajakan di Indonesia.

\section{METODE PELAKSANAAN}

Kegiatan mini sharing bagi anggota Paguyuban Pengusaha Kecil di Perumnas Kota Baru Driyorejo, Gresik, diawali dengan melakukan observasi di lokasi. Observasi tersebut dilakukan 
pada bulan Januari 2019. Observasi dilakukan untuk melihat kondisi para anggota Paguyuban. Hasil yang diperoleh selama kegiatan observasi menunjukkan bahwa anggota paguyuban Pengusaha Kecil tersebut masih belum mempunyai wawasan yang cukup dalam bidang literasi keuangan dan perpajakan. Para anggota di paguyuban tersebut menghendaki agar dilaksanakan kegiatan yang dapat menambah wawasan mereka.

Atas kebutuhan dan permintaan tersebut, kegiatan mini sharing literasi keuangan dan perpajakan bagi anggota paguyuban pengusaha kecil di Perumnas Kota Baru Driyorejo Gresik Jawa Timur dilaksanakan pada tanggal 23 Februari 2019. Kegiatan dilaksanakan di rumah makan Rocket Chicken Perumnas Kota Baru Driyorejo, yang dimulai pada jam 10:00 hingga jam 13:00.

Pelaksana kegiatan terdiri dari tiga orang anggota yang dibantu oleh empat mahasiswa Program Studi Akuntansi. Nara sumber yang terlibat dalam kegiatan tersebut berjumlah empat orang. Nara sumber terdiri dari dosen-dosen dari Program Studi Akuntansi dan Program Studi Manajemen Universitas Ciputra. Para nara sumber menyampaikan materi sesuai dengan keahlian masing-masing. Materi disampaikan kepada peserta melalui media power point. Peserta juga mendapatkan modul yang berisi seluruh meteri yang disampaikan oleh para nara sumber. Peserta yang mendaftarkan untuk hadir dalam acara tersebut sebanyak 35 orang, tetapi yang hadir hanya 25 orang. Hal tersebut karena terkendala hujan deras.

\section{HASIL dan PEMBAHASAN}

KegiatanMini Sharing Literasi Keuangan dan Perpajakan Bagi Paguyuban Pengusaha Kecil di Perumnas Kota Baru Driyorejo Gresik, dilaksanakan pada tanggal 23 Februari 2019. Kegiatan tersebut dilaksanakan di rumah makan Rocket Chicken. Lokasi tersebut dipilih karena berada di lokasi Perumnas Kota Baru Driyorejo Gresik. Sayangnya, ruangan yang digunakan untuk pertemuan kurang representatif. Ruangan sempit sehingga membuat kegiatan tidak leluasa. Ruangan juga kurang nyaman karena kurang bersih dan suhu ruangan cukup panas karena tidak ada pendingin ruangan. Kendala lain yang dialami adalah terjadi hujan deras pada saat acara dilaksanakan. Hal tersebut menghambat peserta untuk mengikuti kegiatan. Sehingga, acara tidak dapat dilaksanakan dengan tepat waktu dan tidak dapat dihadiri oleh semua peserta yang sudah mendaftar. Pelaksana kegiatan berusaha untuk menjemput peserta ke tempat tinggal masing-masing, hingga peserta yang hadir berjumlah 25 orang. Sebanyak sepuluh orang peserta tidak dapat hadir karena kendala hujan deras dan rumah yang jauh, sehingga tidak memungkinkan untuk dijemput.

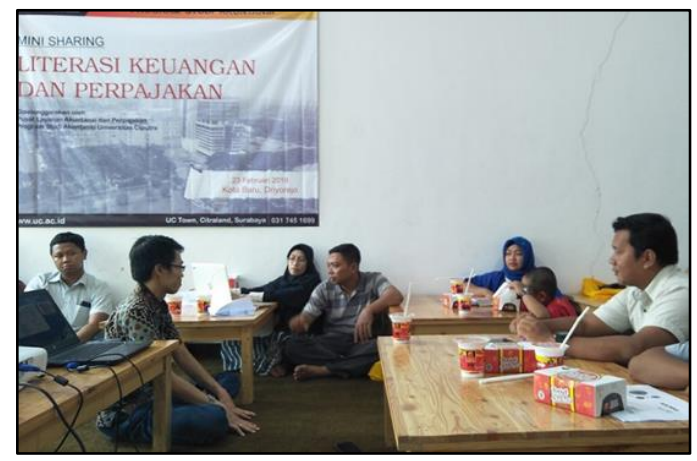

Gambar 2. Pelaksanaan Kegiatan Mini Sharing Literasi Keuangan dan Perpajakan Bagi Paguyuban Pengusaha Kecil di Perumnas Kota Baru Driyorejo Gresik 
Narasumber pertama, menyampaikan tentang strategi pengembangan bisnis kecil. Pengembangan bisnis kecil harus dilaksanakan dengan tawakal percaya pada Tuhan Yang Maha Esa. Sehingga, menjalankan bisnis harus dilakukan dengan jujur, terutama jujur kepada konsumen. Pelaku bisnis juga harus tertib melakukan pencatatan, baik pencatatan keuangan maupun non-keuangan. Catatan keuangan bisnis harus benar-benar dipisahkan dari keuangan keluarga. Karena apabila keuangan bisnis dan keluarga dicampur, maka akan menghambat pengembangan bisnis, bahkan dapat membuat bisnis tersebut tutup. Peserta juga dikenalkan tentang cara mencatat keuangan bisnis dan cara membuat laporan keuangan sederhana untuk bisnis kecil. Melalui laporan keuangan sederhana tersebut, peserta dapat mengetahui apakah bisnisnya menghasilkan keuntungan atau mengalami kerugian.

Narasumber kedua dan ketiga menyampaikan sharing pengalamannya pada saat terlibat dalam pengembangan perusahaan, terutama dalam bidang pemasaran produk. Kegiatan pemasaran penting dilakukan bagi pemilik bisnis kecil. Kegiatan tersebut sangat perlu dilakukan untuk memperkenalkan usaha mereka agar dikenal konsumen secara luas. Berbagai cara pemasaran juga dijelaskan oleh naras umber. Cara pemasaran yang disampaikan naras umber antara lain menggunakan media off line (menyebar brosur, membuat tampilan toko yang menarik, memberikan pelayanan yang menarik, dan sebagainya). Pemasaran dengan menggunakan media online juga diajarkan kepada para peserta. Media online yang diajarkan kepada peserta adalah menggunakan media Instagram.

Nara sumber keempat menyampaikan tentang peraturan perpajakan di Indonesia, terutama bagi pelaku bisnis kecil. Nara sumber juga menyampaikan pentingnya melakukan pelaporan pajak dengan tertib dan tepat waktu. Selanjutnya, cara mengisi laporan dan cara melaporkan pajak, juga diajarkan oleh nara sumber tersebut.

Dalam acara tersebut, para peserta mendapatkan modul. Modul tersebut berisi materi yang disampaikan oleh nara sumber, dengan harapan, peserta selalu dapat mengingat kembali yang harus mereka lakukan dalam menjalankan bisnisnya. Mereka dapat melakukan pencatatan dengan cara yang sesuai bisnisnya. Mereka juga dapat mengingat kewajiban pajak yang harus mereka penuhi.

Setelah peserta mendapatkan wawasan dan pengetahuan tambahan dalam bidang literasi keuangan dan perpajakan, para peserta lebih bersemangat dalam menjalankan bisnisnya. Acara yang diselenggarakan pada bulan Februari tersebut, bertepatan dengan masa pelaporan pajak. Peserta mengajukan permintaan agar mereka mendapatkan konsultasi dalam pembuatan laporan keuangan dan pelaporan pajak. Peserta juga mengajukan permintaan untuk mendapatkan konsultasi strategi bisnis. 


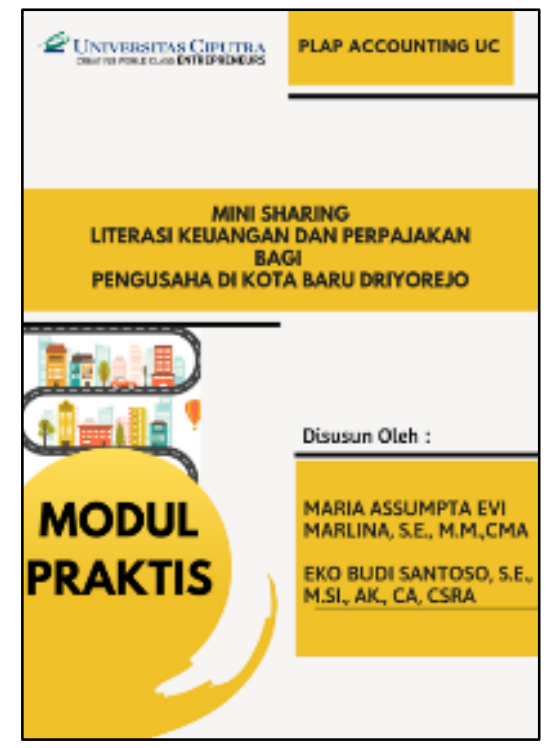

Gambar 3. Modul Mini Sharing Literasi Keuangan dan Perpajakan Bagi Perusahaan di Kota Baru Driyorejo

Antusiasme peserta, yang merupakan pelaku bisnis kecil di lokasi pinggiran kota besar Surabaya, menunjukkan bahwa mereka masih membutuhkan tambahan wawasan, pengetahuan, dan pendampingan dalam menjalankan bisnisnya. Mereka merupakan warga Perumnas Kota Baru Driyorejo Gresik Jawa Timur yang mempunyai latar belakang beragam. Sebagian besar warga berprofesi sebagai karyawan, pedagang, dan pensiunan. Tetapi adapula warga yang belum mendapatkan pekerjaan. Oleh karena itu, penting bagi pihak universitas untuk membantu masyarakat dalam meningkatkan kesejahteraan ekonomi mereka. Kegiatan pengabdian kepada masyarkat yang telah dilakukan oleh Program Studi Akuntansi tersebut diharapkan peserta untuk diteruskan menjadi program konsultasi. Peserta mengharapkan bahwa melalui fasilitas konsultasi yang diberikan oleh nara sumber dapat membantu dalam pemecahan masalah bisnis mereka.

Pelaksana kegiatan pengabdian kepada masyarakat Program Studi Akuntansi Universitas Ciputra mengucapkan terima kasih kepada Lembaga Penelitian dan Pengabdian Masyarakat Universitas Ciputra atas dukungannya yang berupa pendaaan, hingga dapat terselenggara Kegiatan Mini Sharing Literasi Keuangan dan Perpajakan Bagi Paguyuban Pengusaha Kecil di Perumnas Kota Baru Driyorejo Gresik, pada tanggal 23 Februari 2019.

Terima kasih juga disapaikan kepada Bapak Tezar Hariyanto dan Bapak Bambang HP, atas kesediaanya menjadi nara sumber dan dukungannya, selama tim pelaksana kegiatan melakukan observasi di Perumnas KBD Gresik. Terima kasih juga disampaikan kepada Paguyuban Pengusaha Kecil KBD Gresik atas kesediaannya dan dukungannya menjadi mitra kegiatan pengabdian masyarakat Program Studi Akuntansi Universitas Ciputra.

Terima kasih juga disampaikan kepada media masa online beritajatim.com dan wartasas.com, yang telah memberikan kesempatan untuk menyebarluaskan pelaksanaan kegiatan pengabdian masyarakat. Kegiatan tersebut telah dimuat dalam link https://beritajatim.com/ekbis/universitas-ciputra-gelar-literasi-keuangan-dan-pajak/. http://wartasas.com/pendidikan/tingkatkan-kesadaran-wajib-pajak-universitas-ciputraberikan-edukasi-perpajakan-kepada-masyarakat/. 


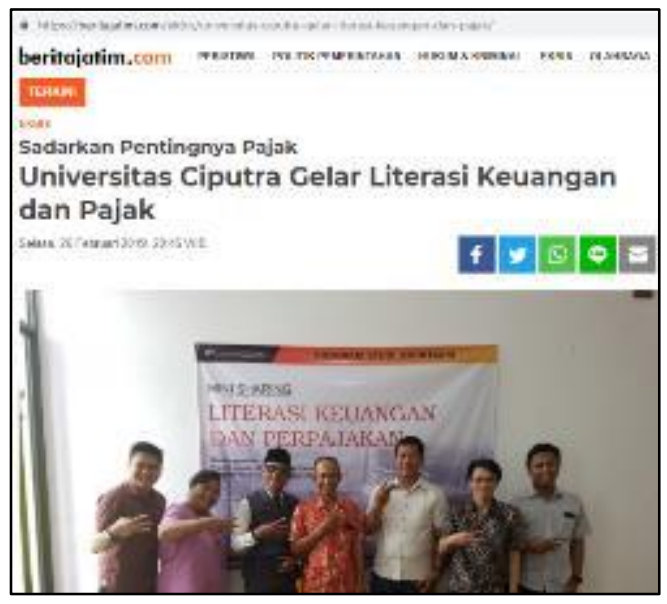

Gambar 4. Publikasi di Media Masa Online Beritajatim.com

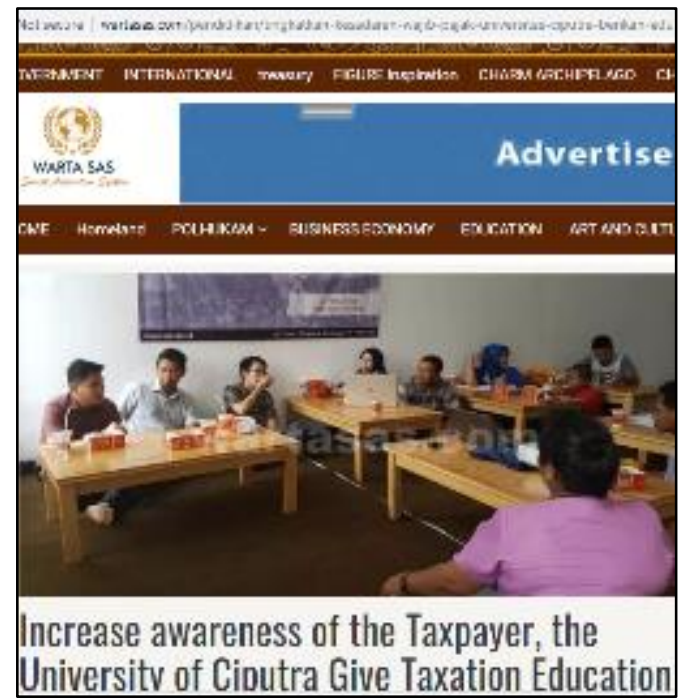

Gambar 5. Publikasi di Media Masa Online Warta Sas

\section{KESIMPULAN}

Kegiatan Mini Sharing Literasi Keuangan dan Perpajakan Bagi Paguyuban Pengusaha Kecil di Perumnas Kota Baru Driyorejo Gresik, mendapatkan resopon antusias peserta. Peserta yang merupakan pengusaha kecil di pinggiran kota besar Surabaya, sangat membutuhkan tambahan wawasan dan pengetahuan baru dalam menjalankan bisnis kecilnya. Hal tersebut sangat penting untuk membantu mereka untuk meningkatkan kulitas kehidupan ekonomi mereka. Kegiatan serupa penting juga dilakukan di wilayah lain dipinggiran kota besar seperti Surabaya, karena sebagian warga mempunyai profesi sebagai pengusaha kecil. Hal tersebut sebagai akibat dari adanya alih fungsi lahan pertanian menjadi lahan pemukiman dan pengembangan industri. 


\section{DAFTAR PUSTAKA}

Pewista, I., \& Harini, R. (2013). Faktor dan Pengaruh Alih Fungsi Lahan Pertanian Terhadap Kondisi Sosial Ekonomi Penduduk di Kabupaten Bantul. Kasus Daerah Perkotaan, Pinggiran dan Pedesaan Tahun 2001-2010. Jurnal Bumi Indonesia, 2(2), 1-8. Retrieved from http://lib.geo.ugm.ac.id/ojs/index.php/jbi/article/view/168

Pribadi, D. O., \& Pauleit, S. (2015). The dynamics of peri-urban agriculture during rapid urbanization of Jabodetabek Metropolitan Area. Land Use Policy, 48, 13-24. https://doi.org/10.1016/j.landusepol.2015.05.009

Prihatin, R. B. (2015). Alih Fungsi Lahan Di Perkotaan (Studi Kasus Di Kota Bandung Dan Yogyakarta). Jurnal Aspirasi, 6(2), 105-118. https://doi.org/10.22212/aspirasi.v6i2.507 